between regional and national level was the key to have these interventions happen rapidly.

\section{P1-86 EPIDEMIOLOGY OF CHILDHOOD ROAD TRAFFIC INJURY: IN BANGLADESH YIELD OF THE LARGEST COMMUNITY BASED SURVEY}

doi:10.1136/jech.2011.142976c.79

\author{
${ }^{1,2}$ M D K ul Baset, ${ }^{*}$ A K M F Rahman, ${ }^{1}$ A Rahman, ${ }^{1}$ S M S R Mashreky, ${ }^{2} E$ Towner. \\ ${ }^{1}$ Centre for Injury Prevention and Research Bangladesh (CIPRB), Dhaka, Bangladesh; \\ ${ }^{2}$ University of the West of England, Bristol, UK
}

Introduction Road traffic injuries (RTIs) are a leading cause of morbidity, disability and mortality in low income countries. $93 \%$ of child road deaths occur in low and middle income countries. Good data are needed to raise awareness of the scale of the problem and to develop and target injury prevention programmes.

Objective Investigate the magnitude of and risk factors for childhood RTIs in Bangladesh.

Methodology A cross sectional study was conducted to determine the current childhood road traffic injury situation in Bangladesh. Face-to-face interviews were used. Multi stage cluster sampling was used to select the sample.

Result Nationally representative data were collected from 171366 rural and urban households. In the sampled households 351651 children aged $0-17$ years were identified; 178285 were males and 173366 females. The rate of non-fatal RTI among children under 18 years of age was calculated as 186.55 per 100000 child-year. The highest incidence (216.06/100 000 child-year) was found among the 5-9 years age group. Among the total children with non-fatal RTI $75.3 \%$ were male and $24.7 \%$ were female. The incidence of childhood RTI was found to be three times higher in rural children than urban children. Most of the childhood RTIs were pedestrian injuries. The rate of fatal RTI was 5.97 per 100000 per year among all children. Conclusion The study has confirmed that childhood RTI is a major public health problem in Bangladesh particularly in rural areas. An appropriate prevention programme is urgently required to prevent fatal and nonfatal RTIs in rural areas.

\section{P1-87 SURVEILLANCE OF DEATH FOR WOMEN OF CHILDBEARING AGE: EXPERIENCE REPORT}

doi:10.1136/jech.2011.142976c.80

M Bastos, * J Armond, S Prado. Universidade de Santo Amaro, São Paulo, SP, Brazil

Introduction Since the establishment of policies of humanisation of delivery and to obtain more accurate data on causes of maternal deaths, maternal mortality in Brazil declined. Pregnant women have been given priority in health services. As a result, we started to notice a large number of deaths of women of childbearing age, not pregnant, who now have more difficulty getting care in health services.

Objectives To identify the causes of death in women of childbearing age (10 to 49 years), to prevent them in the Public Health Unit.

Methods Time series from 2005 to 2009 that evaluated the death certificates of women of childbearing age in the region studied. After checking the main causes of death was held discussion with staff of the Unit on shares, which were immediately put into practice (task force for preventive gynaecological examinations, diagnosis of sexually transmitted diseases, and chronic degenerative diseases).

Results There were 386 deaths of women of childbearing age in the period studied. As causes, undetermined and without care (19.2\%), heart disease $10.9 \%, 10.7 \%$ violent death, cerebrovascular events $6.7 \%$, lung diseases (8.2\%), AIDS $3.6 \%$, maternal causes accounted for $2.07 \%$ and $1.55 \%$ neoplasms. The rate of death between 30 and 49 years rose from $79 \%$ in 2005 to $81 \%$ in 2009 .

Conclusions The most common causes of death were undetermined causes, cardiovascular events and violent death. It appears that prevention and health promotion carried out in health units could prevent such events.

\section{P1-88 DECREASE OF RAILWAY SUICIDES BETWEEN 1998 AND 2006: EVALUATION OF THE GERMAN RAILWAY SUICIDE PREVENTION PROJECT}

doi:10.1136/Jech.2011.142976c.81

${ }^{1} \mathrm{~J}$ Baumert, ${ }^{*} \mathrm{~K}$ Lukaschek, ${ }^{1} \mathrm{~S}$ Kunrath, ${ }^{1,2} \mathrm{~N}$ Erazo, ${ }^{1,2} \mathrm{~K} \mathrm{H}$ Ladwig. ${ }^{1}$ nstitute of Epidemiology II, Helmholtz Zentrum München, Neuherberg, Germany; ${ }^{2}$ Department of Psychosomatic Medicine and Psychotherapy, Klinikum rechts der Isar, Technische Universität München, Munich, Germany

Introduction Railway suicides are a suicidal behaviour which strongly impact psychological and socioeconomic aspects of the railway company, its employees and possible eye witnesses. The German Railway Suicide Prevention Project was carried out in 2002 aimed to prevent suicidal acts on German Railway net by a variety of measurements. The present study evaluated the impact of this project on the number of suicides during an observation period from 1998 to 2006. Methods The data base of the present study is derived from the Event Database Safety (EDS), which is the national central registry of all person accidents in the context of the national German railway company covering the entire German railway track system excluding municipal subway providers. We compared the railway suicide rate 4 years before and after starting the project by defining an "index group" (1998-2001) and a "control group" (2003-2006) using Poisson regression with estimating the average percentage change (APC).

Results The absolute number of suicidal events on the railway track system decreased from 1006 in 1998 to 724 in 2006. The mean suicide rate in the control years was $13.9 \%$ (95\% CI 6.9 to 20.4 ) lower compared to the index years $(p<0.001)$. Adjusting for the overall suicide rate attenuated the decline of the railway suicide rate (APC $4.8 \%, 95 \%$ CI 1.8 to 7.8 ) but significance remained ( $p=0.002$ ). Conclusion The present study revealed a favourable trend with decreasing railway suicide rates even taking the overall suicide rate into account. The preventive measurements carried out by the project might contribute to this development.

\section{P1-89 MILITARY POPULATIONS, MILITARY DISEASES: THE DEVELOPMENT OF MILITARY EPIDEMIOLOGY}

doi:10.1136/jech.2011.142976c.82

${ }^{1}$ B Bergman.* ${ }^{1}$ Army Medical Directorate, Camberley, UK; ${ }^{2}$ Scottish Government, Edinburgh, UK

Introduction In the mid $19^{\text {th }}$ century, military health protection began to be informed by epidemiology. This paper examines the development of military epidemiology and its impact on military health policy.

Methods Historical material drawn from military health reports and other sources is used to illustrate long-term trends and developments.

Results The science of military epidemiology can be traced back to the Scottish Enlightenment of the 18th century. At first qualitative and descriptive, the early nineteenth century saw the development of a more quantitative and analytical approach which became a powerful tool in influencing military policy to protect and improve the poor health of the Victorian soldier, who faced disease and environmental hazards far from home. Formal annual reports on the health of the Army, which were instituted in 1859 and continue to this day, have provided a unique picture of long-term health trends in a changing population. Over time, both the nature of the disease threat and the means of health protection changed, and examples will be given of trends in disease and their impact on military operational effectiveness. The military population itself also 